\title{
LOS PRIMEROS TÍTULOS DE ANAGRAMA Y TUSQUETS. ENSAYO POLÍTICO, CENSURA Y CAMBIO DE RUMBO
}

\author{
Sofía González Gómez \\ (CSIC)
}

\section{LA PULSIÓN POR EL ENSAYO}

Las primeras publicaciones de los sellos barceloneses Anagrama y Tusquets nacieron al calor de un interés notable en España hacia el ensayo político. Su fundación coincide en el tiempo con los procesos de transición a la democracia, y por ello estos dos casos se presentan ilustrativos de los intereses tanto del mercado editorial como de la recepción del público lector en ese periodo histórico, en el que la censura era un agente de la industria de la cultura decisivo. Anagrama y Tusquets son editoriales fundamentalmente conocidas por sus títulos de narrativa, pero esa orientación literaria de sendos catálogos fue posterior, motivada por un fracaso en las ventas del ensayo, que obligó a sus editores, Jorge Herralde y Beatriz de Moura, a redefinir su identidad empresarial. Entre finales de los años 60 y principios de los 70, arco temporal en el que se enmarca este artículo, fueron dos empresarios culturales que contribuyeron a cierta ebullición del género ensayístico en el mercado editorial y a la publicación de obras traducidas hasta entonces inéditas en nuestro país.

En el camino a la democracia había una pulsión editorial que favorecía principalmente al ensayo debido a, principalmente, las lagunas de libros teóricos de ensayo político -y el deficiente nivel de los pocos que circulaban, a causa de la censura y la confrontación- y al deseo de modernización, a una inquietud por parte del público lector de conocer otras lecturas: 
De cara afuera, y vivamente nutridas por el aire viciado y por fin contagioso del extranjero, nacieron algunas editoriales que constituyen hoy verdaderos símbolos de una época en que proliferó el libro que contaba, proponía y discutía cosas en lugar de fabularlas o novelarlas, el libro que trataba de reconectar al lector español con su tiempo histórico [Gracia y Ródenas 2005:118].

La ley de prensa de Fraga (1966), así como la supuesta relajación de la censura [Rojas 2013, Larraz 2014], fueron dos elementos clave en la apuesta por publicar ensayo y en la buena recepción de la que disfrutó el género. Rosa Regàs fundó en 1970 La Gaya Ciencia, que inauguró con la colección "Biblioteca de Divulgación Política", en la que reunió un florilegio de libros divulgativos sobre temas sociopolíticos tratados por reconocidos expertos españoles o personalidades políticas (Josep Melià, Santiago Carrillo, Felipe González, Simón Sánchez Montero, Antonio Álvarez Solís, Joaquín Satrústegui, Manuel Vázquez Montalbán, Federica Montseny, etc.). Esa colección propició que "por vez primera muchos se pusieran a leer breviarios sobre conceptos culpables (...) o de historia política" [Gracia y Ródenas 2008:124]. Regàs seguía la estela de la francesa "Que sais-je?", que desde 1941 publicaba Presses Universitaires de France. Kairós, que al igual que Anagrama viró su catálogo hacia otros ámbitos del conocimiento —en su caso, hacia la psicología y la meditación, principalmente-, publicó El nacimiento de una contracultura (1968) de Theodore Roszack. La contribución de la editorial Planeta al libro político fue la colección Espejo de España, fundada en 1973 y dirigida por Rafael Borràs [Escobar Laplana 2012]. Barral Editores S.A. (Ilamada así tras la ruptura de Carlos Barral con Seix-Barral) comenzó con varias colecciones, entre las cuales se encontraba "Breve Biblioteca de Respuesta", que englobaba traducciones de literatura y ensayo [Martínez Martín 2015:346].

Y, paralelamente a estas grandes empresas, que cito por paradigmáticas en tanto que promotoras de un interés que, en mayor o menor medida, fue menguando, surgieron otros sellos, como Akal, Avance, Ayuso, Ciencia Nueva, Dopesa, Edición de Materiales, Fontanella, Fundamentos, Península, ZYX y EDICUSA. Cabe mencionar que Lumen, editorial capitaneada por Esther Tusquets, cercana a Jorge Herralde y a Beatriz de Moura — formaban parte de lo que se ha denominado gauche divine-, comenzó, por el contrario, publicando libros infantiles [Tusquets 2005:25]. La siguiente cita de Confesiones de una editora poco mentirosa (2005) puede servir como testimonio sobre el hecho de por qué no comenzaron publicando ficción Anagrama y Tusquets, ya que, visto el contexto desde una perspectiva comercial, podría decirse que el ensayo 
era un nicho de mercado que estaba por explotar:

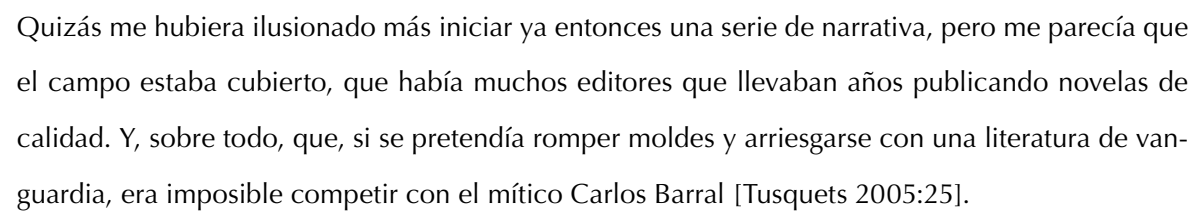

La proliferación de revistas con un sentido amplio de cultura, que incluye una reflexión sobre la vida política y social, muchas de vida ciertamente corta, da cuenta de ese interés. Cuadernos para el Diálogo, Cambio 16, Doblón, Ozono y Posible son algunas de las más conocidas, que se unen a otras más veteranas, como Índice, El Ciervo y Triunfo, y a la lectura clandestina de las que vienen del exilio, principalmente, los Cuadernos del Ruedo Ibérico. Mención aparte merece Ajoblanco (1974-1980), pues constituyó un proyecto cultural de raigambre política con notable relevancia entre los jóvenes de la época, y que puede explicar el interés por lo político:

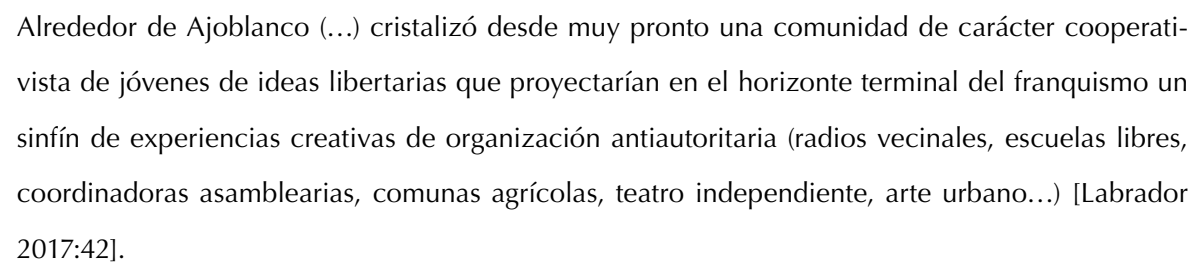

En relación a ese contexto, es significativo el título con el que Francisco Rojas Claros presenta un análisis detallado del boom editorial que se produjo entonces. Se trata de "Tentando el techo de lo editable", en alusión a un informe ministerial de 1969 sobre la producción editorial española [2013:137]. Desde 1968 comenzaron a surgir editoriales que pretendieron introducir el pensamiento de izquierdas en España, quizá tomando como modelo la labor de Éditions Ruedo Ibérico, que contaba entonces con siete años de militancia editorial antifranquista desde Francia. Uno de los primeros sellos fue Ediciones Halcón, que editó la colección "9x18", compuesta por libros marxistas de pequeñas tiradas. Y uno posterior fue Equipo Editorial de San Sebastián, del que destaca su colección "Escuela Social", y que también comprende títulos sobre Marx y Engels. Estas dos se cerraron en 1969, cuando se produjo el estado de excepción durante el cual se frenó el "aperturismo" de Fraga a través de medidas represivas [Rojas Claros 2013:145-147]; y Alberto Corazón Climent Editor, a propósito del cual Rojas Claros recoge el testimonio de Valeriano Bozal, que explica la relevancia de una de las colecciones que iniciaron, 
"Comunicación":

Era en realidad un proyecto editorial de objetivo múltiple, centrado inicialmente en la creación de un "frente cultural" que permitiera publicar en España todos los materiales que fueran necesarios (basados sobre todo en el acervo marxista, cuyos textos serían explicados a través de los prólogos) para constituir un "frente político" de izquierdas y una alternativa global al franquismo que permitiera conquistar las libertades" [Rojas Claros 2013:140].

Cabe mencionar la apuesta de Siglo XXI, editorial mexicana, por España: Siglo XXI de España Editores "contribuyó a la renovación del pensamiento político, sociológico e histórico de nuestro país, porque además, eso era lo que se buscaba desde un principio" [Rojas Claros 2013:143]. Equipo Editorial de San Sebastián, Halcón y otras, como Ciencia Nueva (este sello madrileño publicó por primera vez el Anti-Dühring o la revolución de la ciencia de Eugenio Dühring, de Engels), la editorial Estela, integrada en el grupo de Distribuciones de Enlace, acabarían cerradas por orden del Ministerio, que argumentó que incumplían sus planes editoriales originales [Rojas Claros 2013:150].

En 1968, el Ministerio de Información y Turismo organizó una campaña de fomento de la venta de libros, con el fin de promover la lectura y la publicación de títulos a precios populares. Coincidió con la Feria Nacional del Libro y el propio Ministerio impulsó la iniciativa "Libros de Radiotelevisión" [Rojas Claros 2013:155-156]. Y habría que añadir también que el 24 de noviembre de 1971 un grupo de extrema derecha atentó contra la librería Cinc D'Ors, causando un incendio. Fue el primero de una serie de atentados que se tuvo lugar hasta 1976, y que ilustra, según Rojas Claros, "la clara identificación que se hizo del libro como elemento fundamental en el cambio sociocultural que venía operándose" [2013:248].

\section{NUEVOS PROYECTOS EDITORIALES}

Anagrama y Tusquets son, hoy, dos de las mayores editoriales de literatura española y extranjera en España. Las dos pertenecen, desde hace relativamente poco tiempo, a sendos grupos empresariales (la primera a Feltrinelli y la segunda a Planeta), condición contra la cual las Ilamadas editoriales independientes, surgidas desde finales de la década de los 90, hicieron su bandera. Como cuenta Martínez Martín, cuando surgieron Anagrama, Tusquets, y también 
Lumen, eran percibidas como independientes, adelantando de esa manera el término, que en el actual campo cultural goza de bastante prestigio:

En la dimensión literaria el concepto de pequeño editor no solo hacía referencia a estas características empresariales como empresas individuales y modesto volumen de negocio, sino que tenía una connotación de independencia y escondía la idea misma que tenía de su misión el editor. Equivalía a decir independiente, esto es, a salvo de presiones, compromisos y condicionantes, que no fueran la libre decisión y creencia en lo que se editaba [Martínez Martín, 2015:313].

Y, también, como ocurre ahora, se le adherían al término connotaciones muy positivas, todas ellas alejadas de la vinculación monetaria propia de una empresa, que al fin y al cabo es la estructura base de cualquier sello:

\footnotetext{
El "editor independiente", así calificado o así autodefinido como una orgullosa seña de identidad, era entendido como el ejercicio de una actividad libre por el editor que, a salvo de condicionantes externos, publicaba lo que quería publicar, como un acto de autonomía y de vocación intelectual. Era una postura mesiánica y con la fuerza de las convicciones de quien cree en los principios insobornables de la divulgación cultural más allá de un negocio. Eso exigía una impronta personal, más que colectiva, y una naturaleza individual del negocio [Martínez Martín 2015:370].
}

El caso más ilustrativo de esa impronta personal podría ser el de Lumen, pues como la propia Esther Tusquets cuenta en sus memorias, los primeros títulos de su catálogo se elegían sin más criterio que los gustos personales de ella y su familia. Y, en cuanto a esa autonomía, cabe mencionar el caso de Rosa Regàs, que sufrió graves dificultades económicas cuando se apagó el auge del proyecto de La Gaya Ciencia.

Por esa condición de pequeñas editoriales, precisamente, Anagrama y Tusquets, junto con Barral Editores, Edicions 62, Laia, Fontanella, Cuadernos para el Diálogo y Lumen, formaron parte de Distribuciones de Enlace, una suerte de asociación surgida por iniciativa de Carlos Barral, al que se unió un grupo de socios, formado por Pedro Altares, Carlos Barral, José María Castellet, Alfonso Comín, Beatriz de Moura, Paco Fortuny, Jorge Herralde, Esther Tusquets y Rafael Martínez Alés. De aquella empresa surgió una colección, "Ediciones de Bolsillo", que llegó a editar, según Jorge Herralde, 500 títulos [VV.AA. 2006:218].

Un grupo de editores independientes, antifranquistas — dentro de tendencias muy diversas: pesuqueros, nacionalistas, socialistas, cristianos de izquierdas-, con un toque de sofisticación y exquisitez (...), ocho editores atípicos, que no consideraban que una editorial fuera simplemente 
un negocio más y que vender libros se equiparara a vender chorizos, que creían, por el contrario, que estaban llevando a cabo una importante misión política y cultural [Tusquets 2005:128].

Martínez Martín afirma que el libro de bolsillo era una "cantera de negocio" [2015:346], pero finalmente los nuevos editores se encontraron con más devoluciones de las que habían imaginado [Vila-Sanjuán 2003:50] y, como se explicará a continuación, hubieron de virar hacia otras tendencias en sus respectivos catálogos.

\subsection{ANAGRAMA}

Jorge Herralde fundó Anagrama en 1968 con la intención de convertirse en una editorial combativa fundamentalmente dedicada a la prosa de ideas, como confiesa en 40 años de labor editorial, título que inauguró una colección que homenajeaba la trayectoria del sello:

\footnotetext{
En la década de los 70 la editorial se caracterizó por su dedicación al ensayo, en especial, textos políticos en abierta confrontación con la censura franquista, con no pocos percances, y a incorporar corrientes de pensamiento apenas presentes en la bibliografía española. Asimismo publicamos textos de vanguardias artísticas y narradores también poco habituales, etiquetados como "marginados o forajidos". [Herralde 2005:7].
}

El reconocimiento público de la labor editorial de Herralde, sobre todo por la relevancia de los títulos de su catálogo, es reiterado. Muchos autores han reconocido el prestigio que supuso poder publicar en Anagrama. Al contrario que Esther Tusquets y Beatriz de Moura, Herralde no tenía una vinculación con el mundo editorial de índole familiar:

\footnotetext{
Jorge Herralde Grau fue el paradigma del editor que partía de la nada, en el sentido de no contar con precedentes familiares o personales en el ámbito de la edición, la imprenta o la tipografía, solo animado por su vocación de lector y el compromiso de la divulgación cultural. Un lector convertido en editor sin conocimiento del oficio. Pero no como caso aislado, sino como ejemplificación de las nuevas condiciones del campo editorial de los años sesenta [Martínez Martín 2015:371].
}

La editorial se iba a llamar Crítica, "recogiendo todo el contenido semántico de sus propósitos editoriales" [Martínez Martín 2015: 371], pero finalmente el nombre elegido fue Anagrama ("Cambio en el orden de las letras de una palabra o frase que da lugar a otra palabra o frase distinta, según el $D L E)$. Se le ocurrió cuando se encontraba en la agencia de Carmen Balcells: 
do en las estanterías de la agencia de Carmen Balcells, vi en el lomo de un libro de Feltrinelli el siguiente título. Senso e anagrama, de Renato Barilli. El flechazo fue inmediato: se Ilamaría Anagrama [Herralde 2006:35].

En la actualidad, dieciséis colecciones comprenden el sello (Panorama de narrativas, Narrativas hispánicas, Compactos, Crónicas, Biblioteca de la memoria, Contraseñas, Nuevos Cuadernos Ilustrados, Otra vuelta de tuerca, Zoom, Edición Limitada, Compendium, Literatura Infantil, Llibres Anagrama, La Conjura de la Risa y Contraseñas Ilustradas). Durante los primeros compases de la editorial, el catálogo se encauzó en dos líneas: por un lado, se publicaban prosas de ideas y, por otro, textos vanguardistas; en ambos casos, el fin era el "cuestionamiento de la cloroformizada vida cotidiana de las sociedades burguesas, y la reivindicación de una sexualidad libre, con atención expresa al feminismo y los movimientos gays", según cuenta Sergio Pitol en el prólogo a Opiniones mohicanas. La primera constituyó la colección "Argumentos", impulsada en 1973 por el prestigioso Premio Anagrama de Ensayo [Gracia y Ródenas 2005: 126] $y$, la segunda, "Contraseñas".

Anagrama pretendió, en sus inicios, difundir entre los lectores españoles ensayos de los intelectuales y activistas izquierdistas más influyentes en la cultura de aquella época, como Lenin, Che Guevara y Mao Tsé Tung, entre otros. En la colección "Documentos", hoy desaparecida, ofreció espacio a libros de marcada orientación política:

En su colección Documentos, en 1975 Anagrama publicaba, junto a La oposición obrera, de Alexandra Kollontai — por el que se le abrió un sumario_-, los "documentos fundamentales" del Frente de Liberación de Mozambique, Frelimo, a cargo de Samora Machel. En 1976 una Pequeña antología de Ulrike Meinhof, la líder del grupo terrorista alemán Baader Meinhof que moriría en prisión supuestamente "suicidada" por sus propios guardianes, según se dijo en su día; en 1977 Rosa Luxemburg y la cuestión nacional, de María José Aubet..." [Vila-Sanjuán 2003:54-55].

Los primeros títulos fueron Los procesos de Moscú (1969), de Pierre Broué; Los exiliados románticos (Bakunin, Herzen, Ogarev) (1969), de Edward Hallet Carr; La revuelta del Poder Negro (1969), Floyd B. Barbour (ed.), Los orígenes del socialismo (1970), de George Lichteim; El marxismo (un estudio histórico y crítico) (1970), también de George Lichteim; Crónica de Marx (1972), de Maximilien Rubel; y Los socialistas utópicos (1973), Dominique Desanti, entre otros. Herralde ha reconocido las motivaciones que le llevaron a emprender esa labor de difusión del 
pensamiento de extrema izquierda:

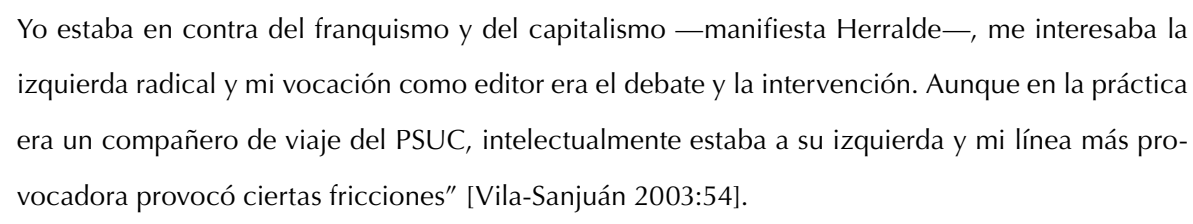

En la colección Argumentos, "se prestaba atención precisamente a todos los debates intelectuales más interesantes de aquel momento, desde el estructuralismo, el freudomarxismo" [Herralde 2005:215]. El primer libro fue Detalles, del filósofo alemán Hans Magnus Enzensberger, publicado por primera vez en Alemania en 1962.

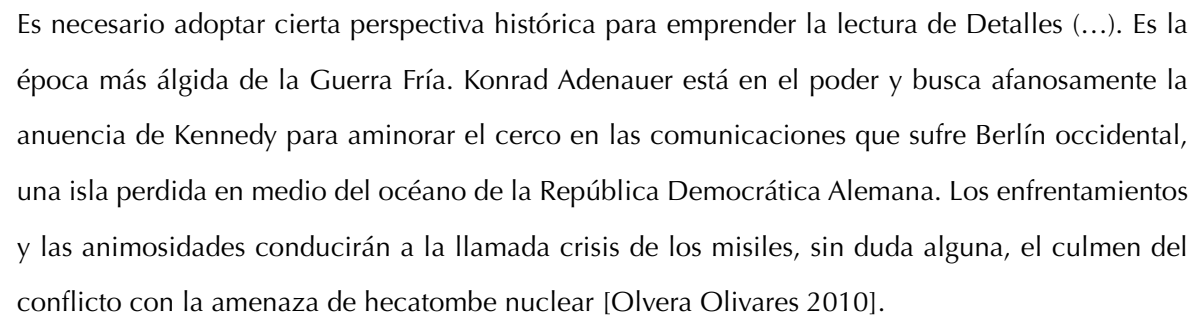

En 1973 tuvo lugar la primera edición del Premio Anagrama de Ensayo, con un jurado compuesto por Hans Magnus Enzensberger, Juan Benet, Salvador Clotas, Luis Goytisolo y Mario Vargas Llosa. El concurso se declaró desierto:

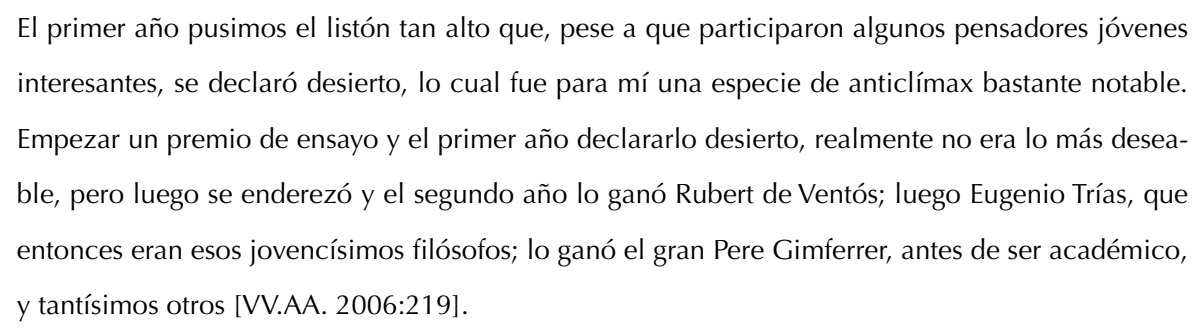

La colección "La Educación Sentimental" (1977-1984) comprende doce títulos (figuran en la página de la editorial, aunque están descatalogados), de autores españoles y extranjeros, relacionados con estudios sobre la sexualidad, el feminismo y el cuerpo, como La condición de la mujer, de Juliet Mitchell; Mujeres en lucha, de Amparo Moreno; La homosexualidad femenina, de Ursula Linnhoff; El nuevo desorden amoroso, de Pascal Bruckner; y Elementos de crítica homosexual, de Mario Mieli, entre otros. Según Vila-Sanjuán, se trataba de "libros con tiradas de 2000 o 3000 ejemplares —nada que ver con los grandes best-sellers de Planeta y de Pla- 
za\&Janés-, pero con amplia incidencia en los sectores juveniles y/o contraculturales del país" [2003:56].

Pese a que había cierto aperturismo gracias a una nueva ley de prensa, el fundador de Anagrama explica que la censura no se terminó y que suponía no pocas dificultades para los libros que deseaban editar:

La colección que tenía que ser central de la editorial en aquel momento, que se llamaba Documentos, eran textos sobre mayo del 68, sobre la revolución cubana, la revolución china, el trotskismo y todo esto que ahora parece tan antiguo y que entonces era vivísimo; pero todo esto lo desmochó la censura de un modo salvaje [VV.AA. 2006:215].

Anagrama hubo de enfrentar en sus primeras publicaciones algunos problemas con la censura - aunque su intervención no se realizó, al contrario de lo que apunta la cita anterior, "de un modo salvaje" -, particularmente con El proceso de Moscú y Los Tupamaros. En junio de 1968, Herralde presentó a consulta voluntaria el primero, obra de Pierre Broué, historiador francés afín al trotskismo. El sello aún se llamaba Editorial Crítica. Meses después, en enero del 69, el aparato censor resolvió autorizar su publicación con tachaduras, después de tres informes: uno de ellos, el correspondiente al original, el otro, al texto traducido, y finalmente el informe del ensayo intervenido. Esta fue la valoración del libro original en francés, a cargo de Fernando Solano:

En 1936-1938 se producen una serie de procesos, en Moscú, contra los viejos teorizadores, activistas y políticos soviéticos. Los procesos de Moscú, dirigidos por Stalin como medio para conseguir la primacía y el monopolio del poder, acaban con la mayoría absoluta de los miembros del Comité Central de 1917-1923, los tres secretarios del Partido de 1917-1921, la mayoría del Politik-Bureau de 1919-1924 y de 108 miembros de los 109 que se componía el Comité Central del Partido Comunista de 1934.

Estos procesos representan un hecho capital en la historia política y de la estructura interna de los métodos comunistas se dirigen contra los compañeros de Lenin, contra Trotsky, y sus amigos, acusados de los peores crímenes por Stalin. Procesos que son, en realidad, una gigantesca depuración, en donde perecen la casi totalidad de los viejos bolcheviques, cuyos miembros son eliminados de los libros de Historia, aunque hoy, rehabilitados por Krutchev, reaparezcan como "víctimas de las calumnias del enemigo".

Esta auténtica matanza muestra bien qué y cuáles métodos son los comunistas. Pero hay un hecho semejante en las actitudes de Stalin y Krutchev: aquel, en un culto personalista depurará a sus contrarios, y este en el hecho de rehabilitarlos no hace sino glorificarlos. 
En la introducción hay matizaciones y definiciones del fascismo (p. 11) indicando ser Franco un fascista (p. 12) y referencias a la Guerra de España de 1936-1949 que deberían ser eliminadas.

En el caso de Los Tupamaros, de Antonio Mercader y Jorge de Vera sobre el Movimiento de Liberación Nacional-Tupamaros de Uruguay, el editor decidió no someter el texto a la consulta previa voluntaria, arriesgándose al secuestro de la edición tras depósito directo. Así ocurrió: después de su presentación, el 27 de enero de 1971, la censura denunció el libro impidiendo cautelarmente su difusión. El 4 de febrero de 1971 tuvo lugar la incoación de Sumario, y el 3 de marzo se procesó a Jorge Herralde.

\begin{abstract}
A pesar de lo manifestado por los autores, y por la propia editorial en la cubierta, este libro sobre los tupamaros no deja lugar a dudas en cuanto a la simpatía con que expone su actividad política. Por un lado se le escapan los elogios (págs.38 y 39) y por otro se constituyen los autores en voceros de la propaganda tupamara (págs.138 a 145) estampando manifiestos y comunicados de tal organización. Por otra parte al establecerse estrategia y su táctica guerrillera, indicando los principios fundamentales en que ambas se basan y se desarrollan, vienen en cierto modo a fomentar por emulación la inserción en tales actividades subversivas, que claramente se manifiestan como marxistas maoístas o pro-chinas, que se confrontan con las actividades de las fuerzas de policía represiva a la que no se elude en calificar de torturadora, así como la consideración de aquellas actividades revolucionarias como meramente políticas, aunque caigan bajo la denominación común de criminales, como pueden verse en los párrafos que se señalan a lápiz rojo en las págs. además de las citadas, 26, 34, 69, a 73, 99, 105, 115, 117, etc. hacen que el libro haya de ser considerado en cierto modo como una apología de la subversión revolucionaria, y por tanto incurso en el apartado f) del art. 2 de la Ley de Orden Público, por lo que no procede la admisión del depósito y si la remisión del libro al Ministerio Fiscal.
\end{abstract}

Madrid, a 27 de enero de 1971

Esta fue la carta que desde Ordenación Editorial enviaron al Ministerio de Información el 2 de febrero de 1971:

Nota para el Excmo. Sr. Ministro

La editorial Anagrama, de Barcelona, presentó directamente a depósito una obra titulada "Los Tupamaros", escrita con evidente simpatía hacia esa organización por Antonio Mercader y Jorge de Vera. Se incluyen también en la obra toda clase de manifiestos y declaraciones de los tupamaros, lo que convierte el libro en un elemento de propaganda de subversiones, especialmente en las actuales circunstancias españolas, reciente la acción clandestina de la ETA.

Por tanto, la obra ha sido denunciada al Magistrado-Juez de Orden Público, al mismo tiempo 
que se ordenaba a nuestra Delegación en Barcelona el secuestro de todos los ejemplares y de los moldes de impresión.

Nuestro asesor, Sr. Herrera, aconsejó también el secuestro y la denuncia.

Además, en el expediente también se puede ver la carta emitida por J. Miguel García, de Visor Libros, en la que informa de que pone a disposición del Tribunal de Orden Público trescientos ejemplares del libro y en la que se compromete a no vender ninguno de ellos, quedando así secuestrada en los almacenes. En 1975, volvieron a solicitar una valoración de Los Tupamaros. En el nuevo depósito figura que lo hicieron "declarando su intención de destinar totalmente a la exportación la tirada oficial de tres mil ejemplares". Se aceptó dos años después, en 1977. Un año después de la denuncia a Los Tupamaros, Anagrama fue incluida en el Informe ministerial sobre las editoriales conflictivas de abril de 1972 como "editorial conflictiva con reiteración" y, en noviembre de 1973, se definió a Herralde como "director propietario excesivamente catalanista" [Rojas Claros 2013:238-239].

\subsection{TUSQUETS}

Beatriz de Moura fundó Tusquets en 1969 después de haber trabajado en las editoriales Gustavo Gili y Salvat Editores, donde ejerció de traductora. Inauguró su catálogo con libros que habían Ilegado a Lumen, cuya brevedad había disuadido a Esther Tusquets de publicarlos. Primero la llamó Tusquets Editor, y en 1977 cambió a Tusquets [Martínez Martín 2015:379-380]. Fundó la editorial en un piso que alquiló al padre de Esther y Óscar Tusquets ${ }^{1}$ —su primer marido—, "alentada por Óscar y con 165.000 pesetas que él sacó, si bien recuerdo, de unas acciones que su padre le había dado en Lumen" [VV.AA. 2006:178-179]. De Moura había estado relacionada con la militancia política:

1 Este es el testimonio de De Moura a propósito de su mudanza:

El padre de Esther y Óscar, además de llevar financiera y comercialmente la Editorial Lumen, tenía varios negocios. Entre otros, construyó un edificio donde le quedó un piso sin vender. Se lo alquilé barato en el acto, sin pensarlo dos veces, por una razón fundamental para mí: dejar de pasar frío. Me había jurado a mí misma, parodiando a Scarlett O’Hara en Lo que el viento se llevó, que ponía a los dioses por testigos de que nunca más pasaría frío. Y así fue, porque ese piso tenía una caldera de leña individual. En ese tercer piso de la avenida Hospital Militar, 52, en el que a finales de los sesenta vivíamos cuatro personas en setenta metros cuadrados, también se instaló Tusquets Editores cuando empezó y allí se quedó hasta bien entrados los setenta. [VV.AA. 2006:176]. 
Yo había militado en el movimiento anarquista, en un grupo que se Ilamaba Mujeres Libres, que no estaba directamente vinculado a la CNT pero tenía relaciones con la organización. Pero me di de baja porque resultaba aburrido, además ya era una pequeña empresaria y a medida que se acercaba la muerte de Franco vimos que la salida no iba por ahí. Pero me había quedado con la idea [Vila-Sanjuán 2003:53].

Tenía, por un lado, la colección "Marginales", formada por textos breves de autores consagrados y caracterizada por su cubierta dorada y, por otro, "Cuadernos Ínfimos", que comprendía ensayos políticos, de cubiertas plateadas [VV.AA. 2006: 1978]. Pero De Moura quería ir más allá: le propuso a Xavier Domingo, "periodista, gastrónomo y provocador connaisseur de temas diversos", que trabajó en Cambio 16, la dirección de Acracia, una nueva colección, y él a su vez le sugirió a Carlos Semprún Maura. Semprún Maura, hermano de Jorge Semprún, era una persona en esa época políticamente muy comprometida con la izquierda. Atesoraba experiencia en el mundo de la edición, pues había dirigido para Ruedo Ibérico la colección "El Viejo Topo", que "se centraba en la historia de los movimientos obreros, aunque en ella apareció también la traducción de La revolución sexual, de Wilhelm Reich" [Rodríguez 2016:2].

Bajo el nombre de Acracia2 "doctrina que propugna la supresión de toda autoridad" (DLE), vieron la luz textos de Kropotkin, Proudhon, Bakunin, Étienne de la Boétie, Pierre Clastres y Cornelius Castoriadis; también, del filósofo español Fernando Savater, y dos libros colectivos, El homosexual ante la sociedad enferma y El terror bajo Lenin [Vila-Sanjuán 2006:53-54]. Beatriz de Moura habla del objetivo de la colección:

La colección Acracia nació, en efecto, de esa tendencia ya marcada, sobre todo en los cuadernos Ínfimos, de suscitar polémica, de ventilar textos refractarios al pensamiento algo granítico de la izquierda marxista tradicional y, por supuesto, al estado de cosas bajo el franquismo [VV.AA. 2006: 184].

Carlos Semprún, en calidad de director de la colección, elaboró una lista de diez títulos para presentarla al Ministerio de Información y Turismo. El ministro, Ricardo de la Cierva ${ }^{3}$, citó a Beatriz de Moura para comunicarle que aprobaba todos los libros, salvo La escuela moderna,

2 Acracia se llamó una revista barcelonesa de Sociología publicada entre 1886 y 1889; desde 1918, un periódico quincenal y una editorial dirigida por Hermoso Plaja, que inició una colección ("Biblioteca Acracia") de cariz filosófico y político [Civantos Urrutia 2017]).

3 Ricardo de la Cierva fue ministro muy poco tiempo, en 1980. A principios de los años setenta fue Director General de Cultura Popular, de la que dependía la censura, puesto que antes había desempeñado Robles Piquer. 
de Ferrer y Guardia [Mengual 2013]. Las incomodidades no se ciñeron al aparato censor, ya que había reticencias por parte de algunos intelectuales de la época, como expone la propia editora:

En aquel momento la izquierda española era muy ortodoxa, y se me echaron encima todos los "padrecitos" por mi iniciativa. Desde Manuel Vázquez Montalbán a Salvador Clotas (célebre crítico de la época) me reprocharon que no estaba bien publicar "eso", los libros en los que yo creía. Todos me criticaron menos Alfonso Carlos Comín (conocido pensador y editor que impulsaba la conciliación de cristianismo y marxismo), quien defendía a capa y espada la libertad de expresión [Vila-Sanjuán 2006:53].

Pero el caso de La escuela moderna, después de consultar el expediente de censura disponible en el Archivo General de la Administración, es diferente; y en realidad el libro que no autorizan es Crítica a Bakunin, de Karl Marx. Lo presentaron a consulta voluntaria el 26 de enero de 1970. Formaba parte de la colección "Cuadernos ínfimos", de escasa longitud (este título en concreto tenía 80 páginas) y de precio popular (cincuenta pesetas). En el informe de censura, el lector expresa el peligro de autorizarla por la posibilidad de difusión:

\footnotetext{
Como indica el título, Marx hace una crítica del pensamiento político de Bakunin expuesto en su obra "Estatismo y Anarquía" en el que estudia la situación en diferentes países europeos. Marx va reproduciendo párrafos, frases y fragmentos de la citada obra, añadiendo por su parte breves comentarios críticos en los que refuta las teorías expuestas al mismo tiempo que expone sus puntos de vista. De esta manera aparecen de forma resumida ambas doctrinas político-sociales.

Aunque en realidad el libro no pasa de ser un enfrentamiento de puntos de vista, el escaso volumen de la obra que más bien es un folleto y su reducido precio la ponen al alcance de cualquier lector sin discriminaciones, convirtiéndose en instrumento de propaganda de las ideologías que ambos representan con el consiguiente peligro.

Estimamos que NO ES AUTORIZABLE la publicación.
}

Continuando con La escuela moderna, fue la editorial Zero la que lo presentó a consulta voluntaria en 1974. Calificada por Roja Claros como "plataforma de lucha" [2006:66] por su labor editorial y su red de distribución, Zero provenía del ámbito religioso y perseguía un propósito claro: "ocupar el vacío, nunca ocupado por el régimen, de la formación cultural y por ende, política) de los trabajadores" [Rojas Claros 2006:67]. Su catálogo basculaba entre textos religiosos y políticos de orientación anarquista y marxista, y 1974 es relevante en su historia porque el sello atravesaba una crisis que concluyó en una escisión [Araus y Sánchez 2015:275]. El aparato censor desestimó su autorización por razones ideológicas: 
Precedida de una introducción de K. Schneider y de un prólogo del anarquista español Anselmo Lorenzo, recoge este libro la conocida obra de F. Ferrer en la que expone su pensamiento fundamentado en el rechazo total de todo principio de autoridad y en el ataque a la Iglesia. El hecho de que esté escrito en época muy pasada no quita, a mi juicio, peligrosidad al tema ni efecto subversivo a la ideología que expone, profundamente anarquista y anticlerical.

Dos años después, en 1976, José Miguel Oriol López Montenegro presentó la obra a consulta voluntaria. Se emitió un informe negativo. La consideran "denunciable" y el 6 de octubre emiten el siguiente informe:

La Editorial solicitó Consulta Voluntaria el 18 de enero de 1974, resuelta desfavorablemente con fecha 1 de febrero del mismo año.

Con fecha 5 de los corrientes la Editorial constituye el preceptivo depósito de ejemplares. El plazo legal expira el próximo día 13.

Indudablemente el contenido del libro es anárquico y profundamente antirreligioso. No obstante todo lo anterior y de lo manifestado especialmente en páginas 11, 15, 25, 51, 99, 100, 101, 113, 170 y 184 , parece difícil encajar el contexto general dentro de la figura de escarnio a la religión Católica del artículo 209 del Código Penal.

A título informativo se manifiesta que según notificaciones confidenciales recogidas en este Servicio los derechos para la publicación del presente libro los tiene la Editorial "Tusquets", comprados al parecer a la hija del Autor, residente en Méjico. Por este motivo existe incluso reclamación judicial por parte de aquella Editorial, que seguramente presentará en fecha inmediata el depósito de la misma obra.

De manera que, efectivamente, no se autoriza la distribución de La escuela moderna, pero no fue a Beatriz de Moura a quien se le comunicó. Ella, de acuerdo con estos documentos, poseía los derechos de la obra.

Tusquets volvió a publicar ensayo en 2001, después de algún tiempo pensando en iniciar una colección de pensamiento e ideas más plural que aquellos primeros títulos:

Nos hacía falta una colección de ensayo propiamente dicho. Sin embargo, seguía haciéndonos falta alguien con cara y ojos que se responsabilizara seriamente de esa área, que fuimos cubriendo más bien a trancas y barrancas. Solo ahora, casi doce años después, hemos dado con el colaborador adecuado en la persona de Miguel Aguilar. De modo que el año próximo, en 2001, sacaremos una nueva colección, titulada Criterios, que cubrirá disciplinas como política, economía y sociedad. Ensayo quedará para filosofía, arte, pensamiento en general [VV.AA. 2006:192].

Actualmente Tusquets publica libros de ensayo, y en su haber tiene títulos de autores 
como Zygmunt Bauman y Rüdiger Safranski, pero no es la colección principal del sello ni mantiene una regularidad tan clara como la de Argumentos de Anagrama.

\section{3. "CAMBIO DE RUMBO"}

Como ya se ha adelantado, las apuestas editoriales por el ensayo no tuvieron la acogida deseada, y mucho menos efectos políticos para la sociedad. Lo que ocurrió fue que los sellos comenzaron a contratar derechos de autores extranjeros que, rápidamente, les granjearon sumas elevadas de ventas, situando los primeros éxitos de venta modernos en el mercado español. Las editoriales antes aglutinadas bajo un mismo grupo, Distribuciones de Enlace, comenzaron a competir por contratos de edición y, sobre todo, a apostar por el género de la novela en detrimento del ensayo político. El campo editorial se profesionalizó, gracias también a personalidades como la agente literaria Carmen Balcells y al empresario José Manuel Lara Bosch, y lo que en un primer momento puede ser visto como un grupo de editoriales independientes, observadas bajo parámetros similares a los que podemos aplicar a los sellos de la misma denominación hoy, se convirtieron en editoriales literarias de una notable envergadura y que actualmente constituyen una parcela dentro del campo editorial español relevante para el circuito literario.

¿Por qué no hubo una continuidad en la publicación de la prosa de ideas, cuyo papel protagonista en Anagrama fue sustituido por la narrativa? Herralde señala dos elementos: por un lado, el desencanto político y, por otro, la pérdida de atracción hacia nuevas lecturas por parte del que hubiera sido su público potencial:

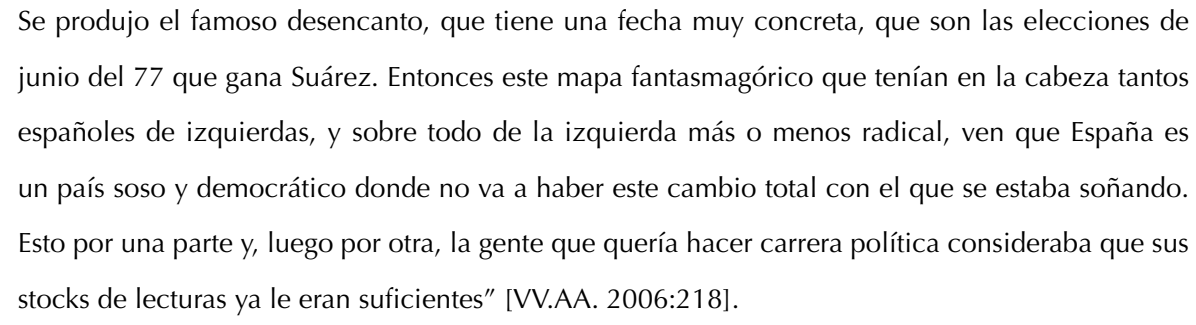

No podemos pasar por alto esa última idea, pues tiene que ver con el cambio de preferencias literarias que se estaba produciendo:

En España, muchos de los que entraron en el PSOE y derivados dejaron de leer y los de extrema izquierda dejaron también de leer no solo política sino ensayo, y fueron derivando hacia lo que 
derivaron muchos de ellos, con lo cual esto afectó a muchas editoriales y sobre todo a todas las revistas que habían tenido un papel importante en todo el trayecto hacia la democracia [VV.AA. 2006:220].

Herralde cuenta en Conversaciones con editores una anécdota muy ilustrativa a propósito de lo que venimos tratando, y que sirve para comprender la evolución lectora: la directora de la librería Cinc D’Ors le manifestó: “Tengo exactamente los mismos clientes, pero antes leían Materialismo y empiriocriticismo, de Lenin, y ahora leen a Patricia Highsmith" [VV.AA. 2006:220]. De manera que se produjo una reorientación hacia la narrativa, a causa de unas "finanzas maltrechas" [VV.AA. 2006:222]. Empezó por La conjura de los necios (John Kennedy Toole) y continuó con varios títulos de Patricia Highsmith. Tusquets, por su parte, inauguró el premio La Sonrisa Vertical con el objetivo de impulsar la literatura erótica, y promueve la colección de narrativa "Andanzas". Como en sus primeros pasos, Anagrama y Tusquets emprendieron proyectos paralelos:

Lo curioso es que dos editoriales de trayectorias paralelas como Anagrama y Tusquets, afectadas además ambas por la crisis que había sufrido la Distribuidora de Enlace, Ilevaran a cabo ese cambio de rumbo mediante colecciones con ciertos rasgos comunes, en un momento en que Tusquets hacía poco tiempo que se había constituido en sociedad anónima con la implicación más intensa de Antonio López Lamadrid (1938-2009) [Mengual 2016].

Estudiar el ensayo, entendido como un texto que ve la luz en formato de libro, desde la óptica de la historia cultural de la edición permite estimar la recepción que tuvo en el periodo de transición a la democracia — como hemos visto, al principio fue fulgurante, pero no tardaron en decaer las ventas, y no llegó a alcanzar las cuotas que vivió Francia en la misma época-; además, permite valorar los catálogos de editoriales tan señeras como Anagrama y Tusquets. Se trata, en ambos casos, de sellos que comenzaron imprimiendo títulos muy políticos con el afán de intervenir, pero también de formar el gusto de un público lector que, a finales de los 70 , empezaba a abrirse a nuevas propuestas culturales, aunque, al final, se demostrara que había una mayor predisposición hacia la narrativa que hacia todos aquellos libros combativos, que no resultaron viables desde el punto de vista comercial. Es significativa la desaparición de las editoriales mencionadas en paralelo con la pérdida progresiva de interés hacia el estructuralismo, el maoísmo, el troskismo y demás corrientes sesentayochistas. Las propuestas editoriales de 
Anagrama y Tusquets nos muestran, en definitiva, una parcela de la realidad de aquella época que evidencia lo que, en un nivel político, acabó ocurriendo, y que de manera global se conoce como el desencanto.

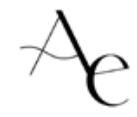

\section{Bibliografía}

ARAUS, Ma del Mar. y SÁNCHEZ, Ana: "Editorial ZYX, S.A.: Editorial obrera frente al Franquismo". Social and Education History 4, 3 (2015), pp. 260-286.

CIVANTOS URRUTIA, Alejandro: Leer en rojo. Auge y caída del libro obrero. Madrid: Fundación de Estudios Libertarios Anselmo Lorenzo, 2017.

ESCOBAR LAPLANA, David: Una colección para la transición. Espejo de España, de la Editorial Planeta (1973-1978). Gijón: Trea, 2012.

GRACIA, Jordi y RÓDENAS DE MOYA, Domingo: El ensayo español. Siglo XX. Barcelona: Crítica, 2005.

HERRALDE, Jorge. Por orden alfabético. Escritores, editores, amigos. Barcelona: Anagrama, 2006.

—. Jorge: 40 años de labor editorial. Barcelona: Anagrama, 2005.

—_ Jorge: Opiniones mohicanas. Barcelona: Acantilado, 2001.

LABRADOR, Germán: Culpables por la literatura. Imaginación política y contracultura en la transición española (1968-1986). Madrid: Akal, 2017.

LARRAZ, Fernando: Letricidio español. Censura y novela durante el franquismo. Gijón: Trea, 2014.

MARTíNEZ MARTíN, Jesús A.: "La Transición editorial: los años setenta", en Martínez Martín, Jesús A. (dir).: Historia de la edición en España (1939-1975). Madrid: Marcial Pons, 2016. 
MENGUAL, Josep: “Las esperadas memorias de Beatriz de Moura" (URL: https://negritasycursivas.wordpress.com/2013/11/01/las-esperadas-memorias-de-beatriz-de-moura-2/) (2013).

OLVERA MIJARES, Raúl: "Primeros ensayos de Enzensberger. El denuedo y el ingenio de un escritor", en Replicante. Cultura crítica y periodismo digital (URL: http://revistareplicante.com/ primeros-ensayos-de-enzensberger/).

ROJAS CLAROS, Francisco: Dirigismo cultural y disidencia editorial en España (1962-1973). Alicante: Servicio de Publicaciones de la Universidad de Alicante, 2015.

—- Francisco: "Poder, disidencia editorial y cambio cultural en España durante los años 60", en Pasado y Memoria, n. ${ }^{\circ} 5$ (2006), pp. 59-80.

RODRÍGUEZ, Juan: "Semblanza de Éditions Ruedo Ibérico (1961- 1982)". En Biblioteca Virtual Miguel de Cervantes - Portal Editores y Editoriales Iberoamericanos (siglos XIX-XXI) - EDI-RED: http://www.cervantesvirtual.com/obra/editions-ruedo-iberico-1961-1982- semblanza/ (2016).

SIMÓ, Marta: "Conciencia democrática e industria editorial en los primeros años de la Transición española: la Biblioteca de divulgación política", en Amnis. Revue de civilisation contemporaine Europes/Amériques, n. ${ }^{\circ} 14$ (2015).

TUSQUETS, Esther: Confesiones de una editora poco mentirosa. Barcelona: RqueR, 2005.

VILA-SANJUÁN, Sergio: Pasando página. Autores y editores en la España democrática. Barcelona: Destino, 2003.

VV.AA.: Conversaciones con editores. En primera persona. Madrid: Fundación Germán Sánchez Ruipérez, 2006. 